\title{
Using Flipped Learning Strategy in Fostering EFL Pre-Service Teachers' Achievement and Motivation
}

\author{
Dr. Howida Mostafa A. Masoud
}

Assistant Professor in Department of Methodology and Instruction (TEFL), Faculty of Education, Minia University, El-Minia-Egypt

\section{Abstract:}

The present study was carried out to investigate the
effectiveness of using a Flipped Learning (FL)
strategy on fostering 4th year English Majors' achievement in methodology course and their motivation towards the course at the Faculty of Education, Minia University. A quasiexperimental pre-post test control group research design was employed. A language teaching program based on FLS was developed by the researcher and used with the treatment group, whereas, the conventional lecture method was used with the non-treatment group. Sixty female and male 4th year English Majors students were randomly chosen and divided into two groups the treatment and the non-treatment groups of the research. Tools of the study included a pre-post achievement test on methodology course, a language teaching FL-based program, a checklist of students' computer literacy and a pre-post motivation scale. Analysis of data (using t-test) revealed that the treatment group significantly outperformed the non treatment one on the post performance of the achievement test. The treatment group significantly improved on the post performance of motivation Scale as well. Discussion of these findings, recommendations and suggestions for further research are presented.

Key Items: Flipped Learning, Achievement, Motivation.

\section{Introduction}

Traditional ways of learning become ineffective with the rapid increase of technology. The role of the learner is no longer a person who comes to school/university to fill up his/her mind with a massive bulk of knowledge and information. Getting access to the internet through mobiles and PC computers make changing the learning environment become an urgent demand. Students need to be acquainted with higher competencies and skills to keep pace with the new technology. Inducing the internet into teaching moves along the process of learningteaching as it allows for a more feasible, exciting, favorable and 
motivating environment which provides better chances for learning. Using the internet is found to be very efficient on promoting students' learning, motivation and attitude in general and language skills in particular as asserted by many studies (e.g. Akdemir et al, 2015, Masoud, 2017).Therefore, it becomes very crucial to apply new technological advanced learning and teaching strategies that put emphasis on the active role of learners and individualized learning. Flipped Learning (FL) has become one of the promising strategies that accomplish the shift from the teacher-centered to learner-centered approach.

\section{Flipped Learning Strategy}

The concept "Flipped learning" was coined by two science teachers, Jonathan Bergmann and Aaron Sams, who decided to use videos as introductory lessons for their students to do as homework in order to have more time for face to face interaction in class (Siegle, 2014). FL acquires a worldwide consideration among educators with the aim of applying more advanced interactive teaching trends using technology. It is considered as one of the applications of the constructivist theory of learning which places great emphasis on the learners' responsibility of their own learning. Its core priority is applying learner-centered models where learners acquire and develop different new ideas through interacting with other classmates, the instructor and the content (Felder, 2012). The core of FL strategy is that the content is provided pre-class and students are more engaged in the application of this content in class. It is a kind of "replacement of homework with in class practices" (Bishop \&Verleger, 2013) or "delivering class work online and doing homework in the classroom" (Kara, 2015). Bergmann \& Sams (2014) provided a simple definition of FL as "What is done at school done at home, homework done at home completed in class". Students learn at their own paces at home through watching a video which allows for more interaction, explanation and engagement during class time. They can easily access the videos at any time and place (Fulton, 2012). FL should not be just providing students some materials to read before class, it should incorporate a real 
"partnership" between students and instructors that creates essential learning experience in class (Talbert, 2014). Consequently, the instructor might have more time to accomplish various learning targets and different learning demands of students. FL strategy provides a favorable active learning environment which motivates students to be involved and engaged.

For teachers to apply FL in their classroom, they need to take into consideration the four main element of this strategy as mentioned by FL Network (FLN, 2014). These key elements are:

- 1- Creating a flexible Environment in which students will be provided with a variety of activities and learning modes which make learning easier and more attractive.

- 2- Providing a new learning culture which encourages the shift from teaching to learning.

- 3- Selecting an international content which enriches higher order thinking skills, active learning and peer tutoring.

- 4- Having professional tutors who are well-prepared to continually monitor students during the course, assess their outcome products and give immediate feedback.

There is a great agreement among scholars (e.g. Mohan, 2018, Mo \& Mao 2017, Kara, 2015, Bergmann \& Sams, 2014and Milman ,2012) on the benefits of using FL strategy: it allows learners to pause and 'rewind' their teacher; it sustains team working in class and provides students a good chance to initiate a discussion with their teachers which is not occurred in traditional class; it provokes higher order thinking skills and it provides active learning environment which offers opportunities for better involvement, interaction, achievement and motivation. This innovative strategy allows time to be devoted to discuss particular topics that entail more illumination or explanation.

Learners' achievement level is so influenced by their motivation towards learning. Related studies have found that an active learning environment improves student motivation levels 
and enriches their learning outcomes (Marchand \& Gutierro, 2011 and Yang \& $\mathrm{Wu}, 2012$ ). Motivation is considered as an important factor in increasing achievement as it is found that students with high motivation have high achievement levels (Kettle, 2013). Utilizing FL strategy can afford a more interactive and engaged learning environment which is not offered by traditional approach which is characterized by "Sage on the Stage".

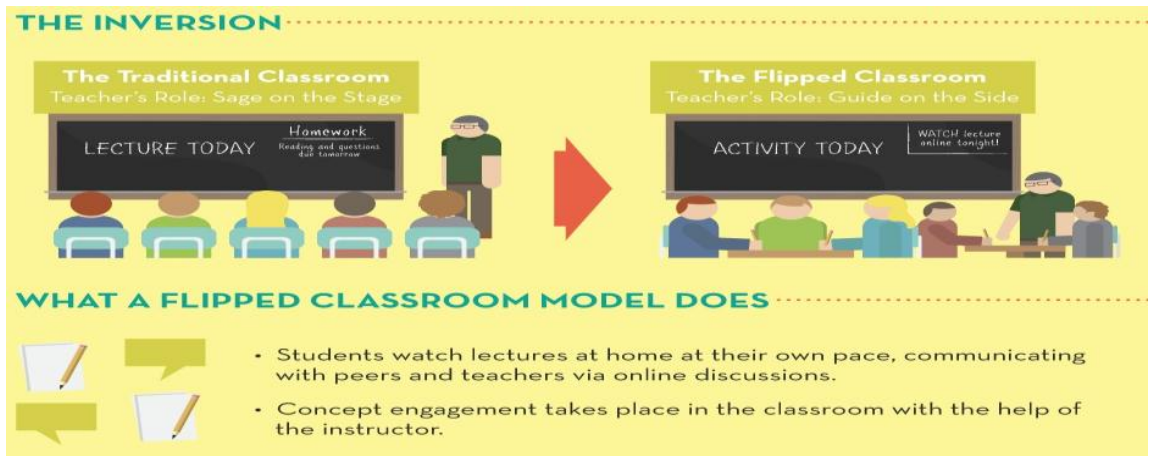

Figure (1) briefly describes the difference between traditional and FL

\section{Literature Review:}

There is a good body of literature indicating the effectiveness of using FL strategy in different educational settings. Bormann (2014) made a literature review of the effectiveness of FL on student engagement and achievement. Findings of the survey indicated that FL model can provide learners with a more interactive and engaging environment that leads to better achievement levels. Some studies referred to the positive effect of FL strategy on students' academic success and achievement and its effective contribution towards their attitudes to learning different subjects. For example, Ekmekçi (2018) made a comparison between FL and traditional face-toface model in writing classes which students perceived as difficult and boring. The researcher attempted to explore the effect of FL on students' writing performance. Analysis of the data showed that the difference between the scores of the experimental and control groups was statistically significant on 
their post writing performance test. The experimental group outperformed the control group in the post administration. Results also revealed that the experimental group showed positive attitudes towards learning writing through using FL model.

Karadagm \& Keskin (2017) examined the impact of activities based on 'Flipped Learning' strategy on students' academic achievement and attitudes toward mathematics in mathematics lessons. An academic achievement test and an attitude scale were used to achieve the purpose of the study. Analysis of the data showed a positive effect of FL strategy on students' achievement and their attitude towards mathematics as well.

A study conducted by Turan \& Goktas (2016) focused on the effectiveness of the flipped classroom method on students' achievement and cognitive load levels. In their study they made a comparison between the flipped classroom method and traditional techniques. Analysis of data showed that students trained through using flipped classroom model got higher learning achievements and lower cognitive loads than those learned with the traditional model. The results of the instructional efficiency indicated that scores of the students in the experimental group were also higher than those of the control group. Hence, they recommended using flipped classroom method as it was found to be a useful and an effective strategy in educational settings.

In another study conducted in Saudi Arabia, Alrowais (2014) measured the effectiveness of FL on students' achievement and attitude. In order to gather the data of the study, the researcher used achievement test and attitudes scale. Findings of the study showed that the experimental group surpassed the control group on the post performance of the achievement test and the attitudes scale. The researcher attributed this improvement to the implementation of FL strategy which developed peer interaction and cooperation 
skills, encouraged student's engagement, and put them in the center of learning.

Other studies revealed that FL fosters students' motivation and makes learning more accessible and easier. In their study, Sirakaya \&Özdemir (2018) attempted to examine the effectiveness of FL model on students' academic achievement, self-directed learning readiness and motivation. They developed certain tools for collecting data of the study such as an achievement test, a self-directed learning readiness scale and a motivation scale. Findings analyzed indicated that the difference between the experimental and the control groups in terms of academic achievement, motivation and retention was significant due to the FL model.

Another study conducted by Aşıssoy \& Özdamlı (2016) they explored the effect of FL on the achievement, motivation and self-sufficiency of students in physics course. An achievement test on physics course, a motivation questionnaire, a physics self-sufficiency scale and semi-structured interviews were used as tools of the study in order to collect data. Findings indicated that the experimental group students achieved higher than the students in the control group. There was also evidence on an increase in motivation and self-sufficiency of the students in the experimental group. Consequently, FL was found to have a positive impact on students' achievement, motivation and selfsufficiency.

Similarly, Abeysekeraa \& Dawson (2015) conducted a study to investigate the effect of FL model on motivation and cognitive load. They constructed a theoretical foundation which basically indicated that Flipped models improved student motivation, and helped manage cognitive load. They also concluded the study with a call for more research into the effectiveness of the flipped classroom approach on different elements.

Reviewing the literature, the researcher found few studies investigated the effect of FL on different aspects of learning the 
language. For Example, Zaki (2017) attempted to examine the effect of FL approach on Students' achievement rates and satisfaction in the British university in Egypt. Data analysis indicated a marked increase in students' achievement rates and showed that students were satisfied with the implementation of the Flipped approach.

Ahmad (2016) investigated the effect of the flipped classroom model on Egyptian EFL students' listening comprehension. The study was conducted in the Faculty of Education, Suez University, Egypt. Results of the study showed significant difference between the pre and post test in favor of the post test. Results also showed the flipped classroom had a significant effect on improving the listening comprehension of Egyptian EFL students.

The previous review of literature revealed the usefulness of FL strategy in fostering learners' achievement and its positive effect on enhancing their general motivation towards learning. However, the majority of these studies were implemented in non-Egyptian settings and very few studies are conducted in Egypt (Zaki, 2017and Ahmad, 2016). But, still these studies are insufficient in the Arab world, particularly in Egypt. To the knowledge of the researcher, no such study is conducted in my area. Consequently, there was an urgent need for conducting an empirical study aiming to investigate and explore the effectiveness of FL strategy on fostering students' achievement and motivation towards learning. It is also an attempt to fill the gap in literature in Egypt. Reviewing the literature helped the researcher state the hypotheses of the study based on the findings of previous studies, design the FL modules and construct the tools of the study: the test, the questionnaire and the motivation scale.

\section{Background of the Problem}

Teaching methodology courses for many years, the researcher noticed that students' scores in methodology tests were very low. A few number of students got high scores whereas the majority of students got low scores. To document 
the problem of the present study, the researcher conducted an informal interview with 30 3rd year and 30 4th year EFL students at the Faculty of Education who were enrolled methodology classes. The purpose of the interview was to investigate and discuss with them the reason behind getting very low score in methodology tests as confirmed from their control sheet at the end of the term in the academic year 2017-2018. Most students asserted that methodology classes were very difficult, disliked, theoretical, uninteresting and not motivating due to the abstract information presented to them without any practical activities. The students complained of insufficient training and activities in learning the different language skills, inadequate method of teaching as it was always lecturing without any application on the different topics included in the course.

To further investigate the problem, the researcher developed a questionnaire aimed at asking EFL 4th year student teachers about the different problems they encounter in learning methods of teaching EFL. Results of the questionnaire affirmed the same weaknesses of the methodology classes presented through the interview. Consequently, newer methods of training pre-service teachers of English are called for. Previous considerations necessitated conducting the present study that attempted to tackle the problems of the students' low achievement in methodology course through using Flipped Learning as an effective technique to enhance their achievement and motivation as well.

\section{Statement of the Problem:}

Based on the results obtained from the questionnaire, the informal interview and students' score in the previous year on methodology test, it became evident that 4th year English Majors need to promote and enhance their achievement level and motivation towards the methodology course. The problem of the present research is manifested in their weakness in methodology course. Such weakness may be attributed to the insufficient training and unsuitable strategies given to students in 
methodology classes. Therefore, they need to enhance their achievement and to investigate their motivation towards the course as well. Reviewing literature, FL strategy is found to be effective for achieving this purpose. Therefore, the present study was an attempt to answer the following question:

- How far is the effect of using Flipped Learning strategy on enhancing achievement level and motivation towards the course of EFL pre-service teachers at the Faculty of Education, Minia University?

- More specifically, this major question was branched into the following questions:

- How far is the effect of using Flipped Learning strategy on enhancing achievement level of EFL pre-service teachers?

- How far is the effect of using Flipped Learning strategy on enhancing motivation towards the course of EFL pre-service teachers?

\section{Objectives of the Study:}

The present study was conducted to achieve the following objectives:

- Enhancing the achievement level of EFL pre-service teachers at the Faculty of Education, Minia University via FL strategy.

- Enhancing motivation towards the course of EFL preservice teachers at the Faculty of Education, Minia University via FL strategy.

\section{Hypotheses of the Study:}

- There would be a statistical significant difference between means of scores obtained by the subjects of the treatment and the non-treatment groups in the post performance on the overall Methodology Achievement test (favoring the treatment group).

- There would be a statistical significant difference between means of scores obtained by the subjects of the 
treatment and the non-treatment groups in the post performance of the sub-domains on the Methodology Achievement test (favoring the treatment group).

- There would be a statistical significant difference between means of scores obtained by the subjects of the treatment and the non-treatment groups in the post performance on the overall Motivation towards the course scale (favoring the treatment group).

- There would be a statistical significant difference between means of scores obtained by the subjects of the treatment and the non-treatment groups in the post performance of the sub-domains on the students' Motivation towards the course (favoring the treatment group).

\section{Significance of the Study:}

The present study was an attempt to respond to the call of the shift from teacher-centered to learner-centered models. The study might be significant to pre-service students as it provides an instructional strategy based on using different activities, exercises and tasks. The findings of the present study could be both theoretically and practically significant for EFL teachers, curriculum designers and researchers. Finally, to the researcher knowledge, this study might be one of the pioneering studies in Egypt to explore the effectiveness of applying FL strategy on EFL students' achievement on methodology course and their motivation towards the course.

\section{Delimitations of the Study:}

- The study was delimited to 60 fourth year English majors at the Faculty of Education, Minia University. Fourth year was chosen particularly, because they are enrolled in a compulsory methodology course in the third and fourth year, so, they can identify the problems and difficulties of the course. In addition, they need to make use of what they learnt in the future profession as teacher. The program would help them have sufficient practice to better perform the tasks required for studying 
the methodology course. The treatment lasted for the whole first term of the academic year 2018-2019, three hours each week, in addition to another two weeks for the pilot study to apply the pre-post tests.

- A Motivation towards the methodology course scale

- The Motivation scale included 30 items and was divided into four basic domains: Students' motivation towards language skills, Utility of the methodology course, Attitudes towards the instructor and Personal goals.

- The study included the main topics that were found important, difficult and not motivating as confirmed by students themselves: teaching composition, teaching reading, teaching culture, teaching speaking, teaching listening, classroom management, assessment, reflective teaching and stating behavioral objectives.

\section{The pilot study:}

The pilot study was conducted two weeks before implementing the program to test the validity and reliability of the instruments. Face validity of all tools was determined by consulting a panel of experts, whereas the internal validity was decided by internal consistency or Cronbach Alpha Coefficient. The reliability of all tools was determined by one or more of the following: Cronbach Alpha Coefficient, test-retest, or the interrater method. The pilot study revealed that all tools were valid and reliable for the actual experimentation

\section{Definitions of Terms: Flipped Learning:}

According to Wikipedia (2018), Flipped Learning is "an instructional strategy and a type of blended learning that reverses the traditional learning environment by delivering instructional content, often online, outside of the classroom while engaging in concepts in the classroom with the guidance of a mentor". Flipped Learning defined as "a pedagogical approach in which the conventional notion of classroom-based learning is inverted, so that students are introduced to the learning material before class, with classroom time then being used to deepen 
understanding through discussion with peers and problemsolving activities facilitated by teachers"(Higher education Academy, 2017). Flipped Learning Network (2014) provided a definition of the term: "Flipped Learning is a pedagogical approach in which direct instruction moves from the group learning space to the individual learning space, and the resulting group space is transformed into a dynamic, interactive learning environment where the educator guides students as they apply concepts and engage creatively in the subject matter".

The researcher operationally defined FL as an instructional video-based tutorial in which students are introduced to learning content prior to being fully engaged actively and cooperatively with peers to accomplish a certain task.

\section{Motivation:}

According to Wikipedia (2018) Motivation is the "reason for people's actions, willingness and goals. It is one's direction to behavior, or what causes a person to want to repeat a behavior, a set of force that acts behind the motives".

Broussard and Garrison (2004) defined motivation as the "attribute that moves us to do or not to do something".

Operationally, motivation is defined as an incentive to accomplish an objective.

\section{Achievement:}

Wikipedia (2018) provided a definition of achievement as "It is the extent to which a student, teacher or institution has achieved their short or long-term educational goals".

Operationally, achievement is considered the level that students reached on their achievement of the methodology course through the scores they got in the test prepared for this purpose.

\section{Variables of the Study:}

Independent Variable:

- Using FL strategy 


\section{Dependent Variables:}

- Fostering students' achievement level on methodology test.

- Developing students' motivation towards the course.

\section{Control Variables:}

- All students are 4th years English Majors.

- Scores of students on the end term methodology test

- Level of performance in the Pre- achievement test

- The results revealed that the difference in the mean scores between the treatment and non-treatment on the Pre- achievement test was not statically significant as shown in table (1).

Table (1) Means, Standard Deviation and t-value between mean scores of the Treatment and non-treatment Groups in the PreAchievement test

\begin{tabular}{|c|c|c|c|c|c|}
\hline No & Group & Mean & S.D & DF & T-value \\
\hline 30 & Treatment & 35.00 & 5.16 & 58 & 0.13 \\
\hline 30 & Non-treatment & 35.17 & 4.64 & & \\
\hline
\end{tabular}

- Not Significant at $0.01 \& 0.05$ levels

\section{Research Design}

A quasi experimental pretest-posttest control group design was employed. A Flipped Learning manual, for fostering students achievement and motivation was developed by the researcher and used with the randomly chosen treatment group, whereas, conventional teaching method was used with the randomly chosen non-treatment group. Thirty male and female students enrolled in the 4th year in the academic year 20182019 formed the treatment group and another 30 formed the non-treatment group. The data of the study were gathered by pre-post achievement test on methodology and a pre-post motivation toward the course scale. The treatment group was trained using the FL strategy.

\section{Instruments of the study}

The researcher developed the following instruments 
- A checklist of students' computer literacy (prepared by the researcher).

- A questionnaire on problems of methodology course (prepared by the researcher).

- An achievement test on EFL methodology course (prepared by the researcher).

- A motivation towards the course scale (prepared by the researcher).

\section{The Questionnaire:}

In order to answer the questions of the research, the researcher developed a questionnaire that tried to find answers for students' low scores on methodology test. It was also an attempt to find out in depth details about the different problems they encounter in learning methods of teaching EFL. Seven TEFL specialists, the jury members, approved the face validity of the questionnaire, its suitability and necessity for the participants. For final form see Appendix (A).

\section{The computer Literacy checklist:}

The computer literacy checklist aimed at identifying the students' skills in using the computer, communicating via e-mail and Facebook, chatting, and surfing the internet. For the validity of the checklist, it was submitted to a jury of 7 qualified and experienced TEFL specialists. They were asked to assess its validity and appropriateness for the purpose of the research. The jury members confirmed the suitability and applicability of the checklist. The students were given the checklist before the administration of the treatment to make sure that all research participants demonstrated the necessary computer skills required for the current research. The checklist consists of eleven items to which students responded with either 'yes' or 'No'. Analysis of the students' responses revealed that all students own computers at home with internet access; they had e-mails and Facebook accounts. They also had basic computer skills: creating PowerPoint files, creating websites, surfing the internet and downloading different types of files (videos, pdf, images, etc.) For final form see Appendix (A). 


\section{The Achievement Test: Objectives:}

This test was designed to:

- 1- Measure 4th year English majors' achievement level in methodology course.

- 2- Ensure equality between the two groups through piloting.

- 3- Measure their performance in the different topics of the course.

- 4- Measure the degree of improvement after the course is over.

\section{Test Construction:}

The achievement test consisted of sixty items representing the most important and emphasized topics of the course. The test consisted of six parts including multiple choice items (For final form, see appendix A).

\section{Scoring:}

One point was given for each test item. The total score is (60) points. Testing time was 90 minutes.

\section{Validity of the Test:}

The test was submitted to a jury of 7 qualified and experienced TEFL specialists.

They were requested to judge the linguistic stating of the items, appropriateness, applicability, clarity and fitness of the items for the participants, and how far the items measure the program objectives. Their suggestions were taken into consideration. They confirmed the suitability and applicability of the test.

\section{The Internal Consistency of the Test Items:}

The validity of the test was determined by computing internal consistency of each item. This was calculated by using (Pearson correlation formula). Correlation between each item and the total sheet of Achievement test ranged from 0.352 to 0.884 (See Appendix B). And Correlation between each domain 
and the total sheet of Achievement test ranged from 0.379 to 0 . 624. All items were significant at (0.01) and (0.05). This indicated the validity of the test as shown in the following table.

Table (2) Correlation Coefficients, Alpha\& $\eta 2$ between each domain and the total sheet of the Achievement test

\begin{tabular}{|c|c|c|c|}
\hline Domain & $\mathbf{R}$ & Alpha & $\eta^{2}$ \\
\hline $\begin{array}{c}\text { Behavioral Objectives \& teaching } \\
\text { methods }\end{array}$ & $0.593 * *$ & $0.835 * *$ & $0.911 * *$ \\
\hline Classroom Management & $0.571 * *$ & $0.801 * *$ & $0.918 * *$ \\
\hline Teaching Reading \& Writing & 0.379* & $0.806 * *$ & $0.917 * *$ \\
\hline Teaching Speaking, Listening & $0.452 * *$ & $0.845 * *$ & $0.895 * *$ \\
\hline Reflective teaching \& Teaching culture & $0.624 * *$ & $0.806 * *$ & $0.929 * *$ \\
\hline Teaching Vocabulary \& Assessment & $0.480 * *$ & $0.798 * *$ & $0.902 * *$ \\
\hline
\end{tabular}

- Significantat0.01level, Significant at 0.05

\section{The Reliability of the Test}

The test was administered to thirty 3nd year English Majors. The data obtained was computed to calculate the reliability coefficient. The reliability coefficient was determined by the test - retest method which was 0.990 . To ensure the reliability of the test, Cronbach Alpha was used and was 0.952 and t-value was 0.021 which was not significant. This indicated that the test enjoys a high degree of reliability as presented in the following table.

Table (3) Correlation Coefficient Alpha's reliability Coefficient between Mean Scores of the Test-re-Test of Achievement Test

\begin{tabular}{|c|c|c|c|c|c|c|c|}
\hline No & Group & Mean & S.D & DF & t-value & R & Alpha \\
\hline 30 & Test & 36.76 & 6.09 & 58 & 0.021 & $0.990 *$ & 0.952* $^{*}$ \\
\cline { 1 - 4 } 30 & Re-test & 36.80 & 6.02 & & & & \\
\hline
\end{tabular}

- Significant at 0.01

\section{Item Analysis: Item Difficulty:}

Responses to individual items were analyzed to determine item difficulty index of this test. The difficulty index of each item ranged from 0.30 to 0.70 . Hence, the difficulty index of the items of this test is quite acceptable (See Appendix B).

\section{Item Discrimination Power:}

Item Discrimination was calculated to determine how well each item discriminates between high and low achievers. To 
achieve this purpose, the researcher separated the highest and the lowest scores on the test. The discriminating items are those answered correctly by more of the higher group than of the lower one. This indicated that the test has a discriminating power as it ranged from 0.40 to 0.75 (For all items, see Appendix B).

\section{The Motivation Scale, Objectives:}

This scale was designed to:

- Assess the students' motivation towards the methodology course.

- Measure the degree of improvement after the course is over.

- Construction of the Scale

The researcher reviewed the literature concerning motivation, its theories, models and scales. Due to some models and scales such as (Gardner's AMBT, 2004) a scale was developed by the researcher in order to measure students' motivation towards learning the methodology course. The scale items were administered to students using a Likert scale. Scoring of the statements ranged from (5) for strong agreement to (1) strong disagreement. The scale included 30 items and four subscales: Students' motivation towards language skills, Utility of the methodology course, Attitudes towards the instructor and Personal goals. Time of the scale was twenty minutes (For final form, see appendix A).

\section{Validity of the Scale:}

The scale was submitted to jury of TEFL experts to assess its validity according to the following criteria: linguistic stating of items, its applicability, relatedness, appropriateness, clarity and fitness. The jury confirmed the suitability and applicability of the scale, hence, confirmed its validity.

\section{The Internal Consistency of the Scale Items:}

The validity of the test was determined by computing internal consistency of each domain. This was calculated by using (Pearson correlation formula). Correlation between each item 
and the total sheet of the Motivation scale ranged from 0.309 to 0. 871 (See Appendix B). And Correlation between each domain and the total sheet of the Motivation scale ranged from 0.638 to 0 . 938. All items were significant at (0.01) and (0.05). This indicated the validity of the scale as shown in the following table.

Table (4) Correlation Coefficients, Alpha\& $\eta 2$ between each domain and the total sheet of the Motivation Scale

\begin{tabular}{|c|c|c|c|c|}
\hline No & Domain & $\mathbf{R}$ & $\eta^{2}$ & Alpha \\
\hline 1. & $\begin{array}{l}\text { Students' motivation towards language } \\
\text { skills }\end{array}$ & 0.938* & 0.996* & $0.872 *$ \\
\hline 2. & Utility of the methodology course & 0.881* & 0.996* & 0.691* \\
\hline 3. & Attitudes towards the instructor & 0.931* & 0.995* & 0.721* \\
\hline 4. & Personal goals & $0.636^{*}$ & 0.987* & $0.444^{*}$ \\
\hline
\end{tabular}

- Significant at 0.01 level

\section{The Reliability of the Scale:}

The scale was administered to thirty 3nd year English Majors. The data obtained was computed to calculate the reliability coefficient. The reliability coefficient 0.992 was determined by the test - retest method. To ensure the reliability of the scale Cronbach Alpha was used and found 0.865 and tvalue was 0.013 which was not significant. This indicated that the scale enjoys a high degree of reliability as presented in the following table.

Table (5) Correlation Coefficient Alpha's reliability Coefficient between Mean Scores of the Test-re-Test of Motivation Scale

\begin{tabular}{|c|c|c|c|c|c|c|c|}
\hline No & Group & Mean & S.D & DF & T-value & R & Alpha \\
\hline 30 & Test & 36.76 & 6.09 & 58 & 0.013 & 0.992* $^{*}$ & 0.865* \\
\hline 30 & Re-test & 36.80 & 6.02 & & & & \\
\hline
\end{tabular}

- Significant at 0.01

\section{Procedures Followed in Teaching and Training the Treatment Group}

- Using the FL strategy, the training sessions were divided into three basic phases: Pre-class (via network site at home), In-class ( 3 hours each week) Post-class (sometimes in class but mostly at home).

- The first session began by face to face interaction. The researcher explained to the students how work was organized throughout the training course. 
- The researcher created an account on Edmodo site and gave the students the code to have access onto the following links(https://new.edmodo.com/groups/flippedlearning-28537258)

(https://new.edmodo.com/groups/26047616)

- Students were divided into groups of five (six groups) to work together throughout the whole training course.

- The pre-class phase was basically intended to provide students with prior, key and essential knowledge on the topics that would be discussed and practiced in class whether through watching a video uploaded from YouTube or reading some content files. Videos and content files were delivered to the students via Edmodo each week. They were allowed up to three or four days to have access to the site to watch the videos or read the material presented and complete the different tasks required from them.

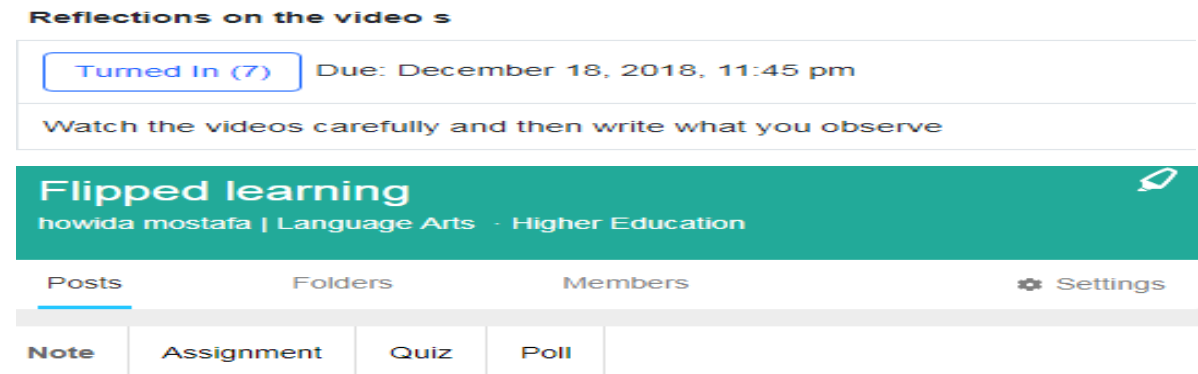

Dear Ss, here is a file about Reflective teaching. Have a look at it

Turned In (2) Due: December 27, 2018, 11:45 pm

The file is on reflective teaching stages

Figure (2) shows a screenshot of the Tasks required from Ss to carry out

- In order to check students' complete engagement in preclass preparation, the researcher developed some quizzes and sometimes asked them to reflect on the videos or write notes on the material presented. Students who executed pre-class tasks were the only ones allowed to participate in the in-class tasks. 


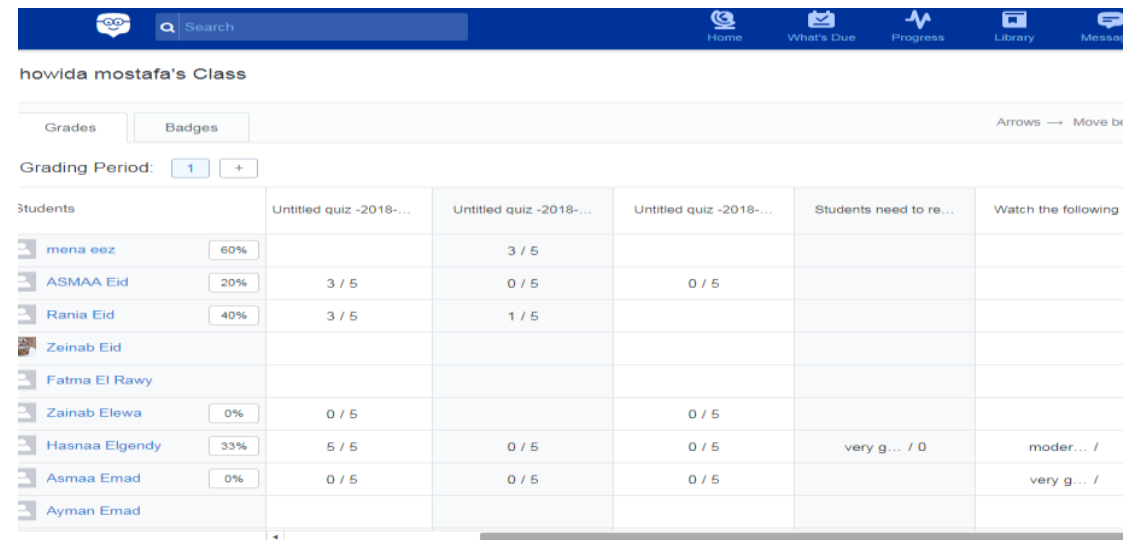

Figure (3) shows a screenshot of the quizzes and Students' grades

- In the pre-class phase, students started chatting with the instructor and with each others to clarify points of difficulty in order to support their understanding of information delivered and to improve their engagement in the in-class activities.

- In the in-class phase, the researcher began the session with a brief introduction (10 minutes presentation using PowerPoint) on each topic to emphasize the information presented previously on the site.

- The in-class phase was devoted to exploring the topics, providing in-depth discussion, generating and exchanging ideas among different groups. Students also applied and practiced different activities in the sessions (e.g. writing different paragraphs, summarizing reading passages, designing mini-tests, practice speaking skills, applying cooperative learning, designing maps for synonyms, antonyms and collocations, etc.)

- Students were encouraged to present their work to get instructive feedback and further suggestions from their 
peers and the tutor. They might present it orally or through PowerPoint.

- In the post-class phase, students were encouraged to sum up the basic ideas presented in the session and evaluate their own and peer's different tasks and projects. They were also encouraged to reflect on their work during the class. This was basically done online via Edmodo but sometimes was done in class whenever there was extra time.

\section{Marwa Reda}

Thank you for the vedio it's very helpful

Reading comprehension is accomplished by asking one self questions in the midst of reading something. Improve a student's understanding and recall of reading material with advice from an experienced teacher in this video education

The goal in teaching reading Sub skills is to increase a student's comprehension and vocabulary, and This can be done by using a variety of texts, such as textbooks, novels, poems, newspaper articles, diaries and advertisement

2 i ikoc

Raghda Sobby

At first really thanks for your efforts to us and I ask my god give you a good recompense.

- Video of writing paragraph, I leaned from this video how do I write a paragraph with simply way through writing the topic sentence which has a main idea, summarizing, supporting details which come after the topic sentence.

- Pre writing stage we can arrange and organize ideas with 6 pre writing steps then 5 steps for writing paragraph and kinds of paragraphs

Like - Reply - Nov 26, 2018, 12:54 AM

Ek ram

This vedio show us how to write a paragraph that is an important thing for us because do not know how to write a paragraph in a good way This vedio show us how to start a paragraph, organize it, organize our thoughts befor writing, and how to end it

After that it shows us the 6 steps of prewriting and the kinds of paragraphs.

\section{Figure (4) shows a screenshot of Students' views and comments}

\section{Findings:}

The present study was conducted to explore how effective teaching the methodology course was through using FL strategy on the treatment group and their motivation towards the course. The "t-test" was utilized for the analysis of data obtained from the achievement test and the motivation towards the course scale. Scores of the participants on the pre-post tests were analyzed and compared. 


\section{Hypothesis (1):}

This hypothesis predicted that the treatment group would score higher on the post application of the overall achievement test. Results showed that the treatment group achieved a higher degree of improvement compared with the non-treatment group on the post administration of the whole achievement test. The mean scores between the treatment and non-treatment group were statistically significant since t-value was (13.95) and Etasquared was (0.984). See Table (6).

Results also pointed out that the difference in the mean scores of the treatment group between the pre-post administrations of the test was statistically significant (Favoring the post administration) as t-value was (13.45) and Eta- squared was (0.962). Consequently, the first hypothesis is confirmed and accepted. See Table (7).

Table (6) Means, Standard Deviation and t-value between mean scores of the Treatment and non-treatment Groups in the PostAchievement test

\begin{tabular}{|c|c|c|c|c|c|c|}
\hline No & Group & Mean & S.D & DF & T-value & $\eta^{2}$ \\
\hline 30 & Treatment & 52.10 & 4.50 & 58 & $13.95^{*}$ & 0.984* $^{*}$ \\
\hline 30 & Non-treatment & 35.33 & 4.64 & & & \\
\hline
\end{tabular}

- Significant at 0.01 level

Table (7) Means, Standard Deviation and t-value $\& \eta 2$ between mean scores of the Treatment Group in the Pre-Post- total Achievement test

\begin{tabular}{|l|c|c|c|c|c|c|}
\hline No & Treatment & Mean & S.D & DF & T-value & $\eta^{2}$ \\
\hline 30 & Pre & 35.00 & 5.15 & 58 & $13.45^{*}$ & 0.962* $^{*}$ \\
\cline { 1 - 3 } 30 & Post & 52.10 & 4.50 & & & \\
\hline
\end{tabular}

- Significant at 0.05 level

\section{Hypothesis (2):}

This hypothesis predicted that the treatment group would score higher on the post application of the achievement test subdomains. Results revealed that the treatment group achieved a significant improvement on each domain of the post achievement test as the difference in the mean scores between the treatment group and non-treatment was statistically significant e.g. (Tvalue for Teaching Vocabulary \& Assessment domain was 11.05, 
for other domains, see Appendix (B). It was also found that the difference in the mean scores of the treatment group between the pre and post administrations was statistically significant.

Results also showed that students got high marks on particular domains, i.e. (Teaching Vocabulary \& Assessment; Teaching Reading \& Writing and Classroom Management) as tvalues were high as shown in table (8).These results illustrate that the enhancement of the treatment group's performance was due to learning through the FL strategy which was found to be effective in promoting students the achievement level of the participants on methodology course. Consequently, the second hypothesis is confirmed and accepted.

Table (8) T-value $\& \eta 2$ between mean scores of the Treatment group in the Pre- Post- Achievement test domains

\begin{tabular}{|l|c|c|c|c|c|c|}
\hline \multicolumn{1}{|c|}{ Domain } & $\begin{array}{c}\text { Mean } \\
\text { Pre }\end{array}$ & $\begin{array}{c}\text { Mean } \\
\text { Post }\end{array}$ & $\begin{array}{c}\text { SD } \\
\text { Pre }\end{array}$ & $\begin{array}{c}\text { SD } \\
\text { Post }\end{array}$ & t-value & $\eta^{2}$ \\
\hline $\begin{array}{l}\text { Behavioral } \\
\text { Objectives \& } \\
\text { teaching methods }\end{array}$ & 6.17 & 8.77 & 2.02 & 1.28 & $5.86^{*}$ & $0.926^{*}$ \\
\hline $\begin{array}{l}\text { Classroom } \\
\text { Management }\end{array}$ & 5.77 & 8.30 & 1.58 & 1.32 & $6.61^{*}$ & $0.958^{*}$ \\
\hline $\begin{array}{l}\text { Teaching Reading \& } \\
\text { Writing }\end{array}$ & 6.23 & 9.33 & 1.73 & 1.14 & $8.10^{*}$ & $0.919^{*}$ \\
\hline $\begin{array}{l}\text { Teaching Speaking } \\
\text { \& Listening }\end{array}$ & 5.80 & 8.23 & 1.81 & 1.33 & $5.82^{*}$ & $0.926^{*}$ \\
\hline $\begin{array}{l}\text { Reflective teaching } \\
\text { \&Teaching culture }\end{array}$ & 5.93 & 8.10 & 1.77 & 1.39 & $5.20^{*}$ & $0.938^{*}$ \\
\hline $\begin{array}{l}\text { Teaching } \\
\text { Vocabulary \& } \\
\text { Assessment }\end{array}$ & 5.10 & 9.36 & 1.42 & 0.91 & $13.61^{*}$ & $0.923^{*}$ \\
\hline
\end{tabular}

- Significant at 0.01 levels

\section{Hypothesis (3):}

This hypothesis predicted that the treatment group would score higher on the post application of the overall motivation scale. Results showed that the treatment group achieved a higher degree of improvement compared with the non-treatment group on the post administration of the whole motivation scale. The mean scores between the treatment and non-treatment group were statistically significant since t-value was (10.25) and Etasquared was (0.951) (See Table (9). 
Results also pointed out that the difference in the mean scores of the treatment group between the pre-post administrations of the scale was statistically significant (Favoring the post administration) as t-value was (10.19) and Eta- squared was (0.970). These results illustrate that the enhancement of the treatment group's performance was due to learning through the FL strategy which was found to be effective in promoting students' achievement level of the participants on methodology course. Consequently, the third hypothesis is confirmed and accepted (See Table (10).

Table (9) Means, Standard Deviation and t-value between mean scores of the Treatment \&Non-treatment Groups in the Post-

Motivation Scale

\begin{tabular}{|c|c|c|c|c|c|c|}
\hline No & Group & Mean & S.D & DF & T-value & $\eta^{2}$ \\
\hline 30 & Treatment & 109.33 & 16.30 & 58 & $10.25^{*}$ & 0.951* $^{*}$ \\
\hline 30 & Non-treatment & 73.17 & 9.76 & & & \\
\hline
\end{tabular}

- Significant at 0.01

Table (10) Means, Standard Deviation and t-value between mean scores of the Treatment in the Pre-Post- Motivation Scale

\begin{tabular}{|l|c|c|c|c|c|c|}
\hline No & Group & Mean & S.D & DF & T-value & $\boldsymbol{\eta}^{2}$ \\
\hline 30 & Pre & 73.33 & $\mathbf{1 6 . 3 0}$ & $\mathbf{5 8}$ & $\mathbf{1 0 . 1 9}^{*}$ & $\mathbf{0 . 9 7 0}^{*}$ \\
\hline 30 & Post & 109.33 & $\mathbf{9 . 8 4}$ & & & \\
\hline
\end{tabular}

- Significant at 0.01

\section{Hypothesis (4):}

This hypothesis predicted that the treatment group would score higher on the post application of the motivation scale subdomains. Results revealed that the treatment group achieved a significant improvement on each domain of the post motivation scale as the difference in the mean scores between the treatment group and non-treatment was statistically significant e.g. (Tvalue for Utility of the methodology course was12.80, for other domains, see Appendix (B).

It was found that the difference in the mean scores of the treatment group between the pre and the post administrations was statistically significant. Results also showed that students got high marks on particular domains, i.e. (Utility of the methodology course; Students' motivation towards language 
skills, Attitudes towards the instructor and Personal goals) as tvalues were high as shown in table (11). These results illustrate that students of the treatment group improved significantly in their motivation towards the course, particularly, in the utility domain due to learning through the FL strategy. This also indicates that students found the strategy very useful and efficient for them. Consequently, the third hypothesis is confirmed and accepted.

Table (11) T-value $\& \eta 2$ between mean scores of the Treatment group in the Pre- Post- Motivation Scale domains

\begin{tabular}{|c|c|c|c|c|c|c|c|}
\hline NO & Domain & $\begin{array}{l}\text { Mean } \\
\text { Pre }\end{array}$ & $\begin{array}{l}\text { Mean } \\
\text { Post }\end{array}$ & $\begin{array}{l}\text { SD } \\
\text { Pre }\end{array}$ & $\begin{array}{c}\text { SD } \\
\text { Post }\end{array}$ & t-value & $\eta^{2}$ \\
\hline 1 & $\begin{array}{l}\text { Students' } \\
\text { motivation } \\
\text { towards } \\
\text { language skills }\end{array}$ & 24.77 & 37.20 & 4.53 & 4.23 & $10.80 *$ & $0.983 *$ \\
\hline 2 & $\begin{array}{l}\text { Utility of the } \\
\text { methodology } \\
\text { course }\end{array}$ & 21.50 & 35.80 & 5.41 & 2.60 & $12.84^{*}$ & 0.986* \\
\hline 3 & $\begin{array}{l}\text { Attitudes } \\
\text { towards the } \\
\text { instructor }\end{array}$ & 15.30 & 21.37 & 5.40 & 2.80 & $5.42^{*}$ & 0.979* \\
\hline 4 & Personal goals & 11.77 & 15.97 & 3.74 & 1.60 & 4.24* & 0.961* \\
\hline
\end{tabular}

\section{-Significant at 0.01 levels}

\section{Discussion:}

Findings of the research have proved that there is a superiority of the treatment group compared with the nontreatment group as the scores of the treatment group were higher than those of the non-treatment group on the achievement test. Findings also have indicated a significant improvement of the treatment group's motivation towards the methodology course. The researcher attributes this superiority to the diverse, unconventional learning experiences, skills and activities employed through the implementation of FL strategy on teaching the treatment group in the in-class phase. Using FL strategy in the current study was found to be effective and useful for the participants. It had a significant influence in increasing students' achievement in methodology course. FL strategy provided students with an interesting and enjoyable learning 
environment which was effective in their learning and contributed to fostering both their achievement and motivation. It gave them an opportunity to explore and discuss the topic to read and hence understood it. It also enabled students to better express themselves, ideas, impressions, reflections within the group and it made learning easier and motivating. FL strategy provided the students with good opportunities to practice the language in class and many of the activities used were so funny (e.g. describing different pictures and turn taking in speaking; using symbols and body language in culture; skimming and scanning in reading, revising and editing each other's paragraphs, etc.) which inspired their interest, consideration and attention. FL strategy developed and enriched students' knowledge, attitude, motivation and experiences. These results are in line with (Sirakaya \& Özdemir, 2018 and Turan \& Goktas, 2016).

FL strategy focused on learners, who worked cooperatively, exchanged ideas, expressed opinions and shared experiences to perform certain tasks. Students were actively engaged in the inclass phase which increases their inspiration to learn. Using pair work and group work throughout tasks increased the talking time of students and lowered their reluctance to talk in front of the whole class. Thus, it could increase their motivation to participate. Each task had a clear outcome that helped students to focus and define their target easily. Students also found these tasks and activities useful and effective since they were built on authentic, daily language use similar to the results presented in the studies Karadagm\& Keskin (2017) and Ekmekçi, (2018). Besides, they were satisfied that they had many chances to practice newly learned information related to a different topic in each task. Moreover, the direct and clear guidelines and content presented in the videos and other instructional materials at the pre-class stage helped to create interest and eagerness for more detailed and deeper investigation of topics in class. It also increased their involvement, and willingness to practice language skills and share ideas among the different groups. Using the videos was so enriching and very effective as they provided 
the students with the key fundamental information and knowledge on what they would do in the in-class phase. This is in accordance with (Zaki, 2017 and Alrowais, 2014).

Checking students' understanding of the material presented in the pre-class phase through quizzes helped to solve any misunderstanding and confusion before in-class phase. This helped the instructor to decide which parts needed more concentration. Assessing each other work, reporting and presenting the task helped students rethink their performance throughout group discussion with the instructor and gave them a sense of confidence, motivation and willingness to take part. .The majority of students enjoyed talking in front of their peers, making presentations and expressing their viewpoints as revealed in their reflection on applying FL strategy.

Structuring the class on FL strategy increased the amount of time the instructor spend working, monitoring and guiding students in class. It also increases the opportunities for students to be engaged in different group activities which were very effective and had an impact on their motivation towards methodology course. Infusing technology into teaching through applying FL helped the researcher to deliver different content materials and instructional videos outside class so that in class time was devoted to face-to-face interaction, providing opportunity to identify and clarify difficulties among students compared with a traditional 'chalk and talk' classroom. Therefore, the implementation of FL strategy in the teachinglearning process was a kind of interest and enjoyment for both the instructor and the students.

\section{Students' reflections:}

- "I enjoyed the course using FL as I really liked going to class understanding

- what I would do in class".

- "Really, for me it was very useful as I learnt at home by my own and followed by more explanation and practice in class". 
- "I liked getting information using videos as I prefer watching materials $\mathrm{t}$ understand more and completing the discussion with the doctor was so valuable".

- "I liked chatting with the doctor for more clarification and discussion of unclear ideas before class to have more time in class for practicing which we never do in courses".

- "I honestly enjoyed the course as I learnt through a different method which was so interesting and motivated me so much to search for more information about the topic".

- "For me I feel that I'm so important in this method because I participated in every step which helped me to learn and hold other discussions with my friends on Edmodo site for more clarification and sometimes we asked the doctor to participate as well. This was very useful and interesting".

- "I liked getting feedback from the doctor on assignment and quizzes because I like to know where I am". For more reflections, see Appendix (B)

\section{Conclusion:}

Considering the literature review, the results of the study and students' reflections on the study, the study highlights the effectiveness of FL as an active strategy in the context of a Methodology course. FL is found quite useful and efficient in fostering students' achievement and developing their motivation towards the course. This implied that utilizing new teaching methods in the teaching-learning process increases students' engagement and involvement in their learning which is considered as a requirement for the new era. The current findings are so encouraging and promising to apply FL in different courses to prepare prospective teachers equipped with higher order thinking skills and higher rates of motivation and achievement. The findings also emphasize that providing students with such an innovative, safe, active and motivating learning environment, which occurred in Flipped Learning, increases the possibility of their success and learning. The implementation of the present study showed that students could 
successfully hold the responsibility of their own learning if they are offered a comfortable, relax, secure and motivating learning environment.

\section{Suggestions for further Research:}

Studies could be done to investigate:

- The effect of using FL strategy on developing students' writing skills.

- The effect of using FL strategy on developing students' critical thinking skills.

- The effectiveness of using FL strategy on improving students' self-esteem.

- The effectiveness of using FL strategy on enhancing students' higher order thinking skills.

- The effectiveness of using FL strategy on enhancing students' oral-aural skills.

\section{References:}

Ahmad, Z.S. (2016).The Flipped Classroom Model to Develop Egyptian EFL Students' Listening Comprehension. English Language Teaching. 9 (9), 166-179.

Akdemir, 0., Bicer, D. and R. Parmaksız S. (2015). Prospective Teachers Information and Communication Technology Metaphors. World Journal on Educational Technology. 7(1).

Alrowais, S.A. (2014). The Impact of Flipped Learning on Achievement and Attitudes in Higher Education. International Journal for Cross-Disciplinary Subjects in Education (IJCDSE).4(1).1914-1921.

Abeysekeraa, L. and Dawson, P. (2015).Motivation and cognitive load in the flipped classroom: definition, rationale and a call for research. Higher Education Research \& Development. Availableat:http://www.tandfonline.com/doi/abs/10.1080 /07294360.

Aşıksoy, G. and Özdamlı, A. (2016). Flipped Classroom adapted to the ARCS Model of Motivation and applied to a Physics 
Course. Eurasia Journal of Mathematics, Science \& Technology Education. 12(6), 1589-1603

Bergmann, J. and Sams, A. (2014). Flipping for mastery. Educational Leadership, 71(4), 24-29.

Bishop, J. L. and Verleger, M. A. (2013). The Flipped Classroom: A Survey of the Research. 120th ASEE Annual Conference Exposition. Atlanta: GA.

Bormann, J. (2014) Affordances of Flipped Learning and its effects on student engagement and achievement. Graduate Research Papers. https://scholarworks.uni.edu/grp

Broussard, S. C. and Garrison, M. E. B. (2004). The Relationship between Classroom Motivation and Academic Achievement in Elementary School-aged Children. Family and Consumer Sciences Research Journal.33(2), 106-120.

Butzler, B.K. (2014). The Effects of Motivation on Achievement and Satisfaction in a Flipped Classroom Learning Environment. Published by ProQuest LLC. Unpublished Disseration.

Ekmekçi, E. (2018). The flipped writing classroom in Turkish EFL context: A comparative study on a new model. Turkish Online Journal of Distance Education. 18(2):1820 .

Felder, R.M. (2012). Engineering education-A tale of two paradigms. In SFGE, 2nd. Int Conf on Geotechnical EngineeringEducation,Galway.www4.ncsu.edu/unity/locke rs.

Flipped Learning Network (2014).What is a Flipped Learning? http://fln.schoolwires.net/cms/

Fulton, K. (2012) Upside down and Inside Out: Flip your Classroom to Improve Student Learning. Learning \& LeadingwithTechnology. https:// files. eric.ed .gov/ fulltext /EJ982840

Gardner, R. (2004). Language Learning Motivation: The student, the teacher, and the researcher. Foreign Language Education, 6 (1),1-18. 
Higher Education Academy (2017). Flipped Learning. https://www.heacademy.ac.uk.

Kara, C. (2015). Flipped classroom. Turkish Thoracic Society, 9, 224-228.

Karadag, R. and Keskin, S. S. (2017). The effects of Flipped Learning approach on the academic achievement and attitudes of the students. New Trends and Issues Proceedings on Humanities and Social Sciences. 4 (6), 158168. https://www.researchgate.net

Kettle, M. (2013). Flipped physics. Physics Education. 48(5). doi: $10.1088 / 0031$

Kong, S. C. (2014). Developing information literacy and critical thinking skills through domain knowledge learning in digital classrooms: an experience of practicing flipped classroom strategy. Computers \& Education. 78, 160-173.

Marchand, G.C. and Gutierrez, A.P. (2012). The role of emotion in the learning process: Comparisons between online and face-to-face learning settings. Internet and Higher Education.

Masoud, A.H.M. (2017). Using a WebQuest Based-Program in Fostering English Majors' Reading Comprehension Skills and Their Attitudes Towards Reading. Egyptian Council for Curriculum \& Instruction. , Vol. 228, 42-77

Milman, N. (2012). The flipped classroom strategy: What is it and how can it best be used. Distance Learning. 9(2), 85-87.

Mo, J. and Mao, C. (2017). An Empirical Study on the Effectiveness of College English Reading Classroom Teaching in the Flipped Classroom Paradigm. Revista de la Facultad de Ingeniería. 32(10),632-639,

Mohan, D. (2018). Flipped Classroom. Flipped Teaching and Flipped Learning in the Foreign/Second Language PostSecondaryClassroom.11,1-20 https:/ /journal .lib. uogue lph .ca/index.php/nrsc/ 
Siegle, D. (2014). Technology: Differentiating instruction by flipping the classroom. Gifted Child Today, 37(1), 51-72.

Sirakaya, A.D. and Özdemir, S. (2018). The Effect of a Flipped Classroom Model on Academic Achievement, self-Directed Learning readiness, Motivation and Retention. Malaysian Online Journal of Educational Technology. 6 (1),76-91

Talbert, R. (2014). Flipped Learning Skepticism: Can students reallylearnontheirown?http://www.chronicle.com/blognet work/castingoutnines/

Turan, Z. and Goktas, Y. (2016). The flipped classroom: Instructional efficiency and impact on achievement and cognitive load levels. Journal of E-Learning and Knowledge Society.

https://www.researchgate.net/publication

Wikipedia (2018). https://en.wikipedia.org/wiki/Flipped classroom

Yang, Y. and $\mathrm{Wu}, \mathrm{W}$. (2012). Digital storytelling for enhancing student academic achievement, critical thinking and learning motivation: A year-long experimental study. ComputersandEducatio59,339-352.doi:10.1016/j.compedu . 2011.12.012

Zaki. A.T. (2017). A Developmental Study of the Flipped Classroom Approach on Students' Learning in English Language Modules in British University in Egypt. World Academy of science, Engineering and technology. International Journal of Educational and Pedagogical Sciences. 11(8). 